\title{
JUSTIÇA INTERNACIONAL E DIREITOS HUMANOS: uma abordagem contratualista
}

\author{
Marcelo de Araujo*
}

RESUMO - Minha intenção é mostrar, contra o realismo em relações internacionais, que, ao abordarmos os conceitos de justiça internacional e de direitos humanos, a partir de uma perspectiva contratualista, o denominado conflito entre o interesse nacional e as exigências da moralidade se mostra bem menos problemático. Apresento os principais argumentos em favor do contratualismo através de uma reconstrução da teoria moral de David Gauthier. Em seguida, procuro mostrar que o tipo de contratualismo defendido por Rawls e seus seguidores não é capaz de evitar as críticas feitas pelo realismo à tentativa de defendermos uma concepção de justiça e de direitos humanos no âmbito das relações internacionais.

PALAVRAS-CHAVE - Contratualismo. Realismo. Direitos humanos. David Gauthier. John Rawls.
ABSTRACT - In this paper I argue against realism in international relations by showing that a contractarian approach to the concepts of international justice and human rights renders the socalled conflict between national interest and morality far less pressing than it seems to be. I discuss the thrust of the contractarian approach by means of a presentation of David Gauthier's moral theory. Then, I show that the kind of contractarian approach advanced by Rawls and his followers is not able to counter the realist contention against the ideas of justice and human rights in the context of international relations.

KEY WORDS - Contractarianism. Realism. Human rights. David Gauthier. John Rawls.

\section{I}

Nas últimas décadas, tem havido um intenso debate sobre se, e em que medida, as exigências expressas no ideal de respeito aos direitos humanos devem ter algum tipo de precedência sobre o princípio político da não-intervenção nos assuntos internos de um outro Estado. Esta é uma discussão importante porque, o texto da Constituição da maior parte dos Estados democráticos modernos faz referência, de modo geral, tanto ao princípio moral da "prevalência" dos direitos humanos quanto ao princípio político da não-intervenção. ${ }^{1}$ Ao longo da tradição

Universidade Estadual do Rio de Janeiro - UERJ/Pronex.

A Constituição brasileira de 1988, por exemplo, no início do artigo quarto do Preâmbulo, afirma o seguinte: "A República Federativa do Brasil rege-se nas suas relações internacionais pelos seguintes princípios: (i) independência nacional; (ii) prevalência dos direitos humanos; (iii) autodeterminação dos povos; (iv) não-intervenção; (v) igualdade entre Estados."

\begin{tabular}{|l|l|l|l|l|l|}
\hline VERITAS & Porto Alegre & v. 52 & n. 1 & Março 2007 & p. 137-165 \\
\hline
\end{tabular}


do pensamento político moderno a conciliação entre esses dois princípios normativos jamais constituiu realmente um problema, pois os direitos humanos foram tradicionalmente concebidos como uma questão de política doméstica. Com efeito, a referência à "prevalência dos direitos humanos" foi vista durante muito tempo como um tipo de política que visa, em primeira instância, impor à esfera de atuação do Estado um limite no que concerne ao modo como o Estado deve tratar seus próprios cidadãos. Neste sentido, um Estado só pode ser considerado justo se ele respeitar os direitos mais fundamentais dos cidadãos que vivem no interior de suas fronteiras. Assim, uma boa parte da tradição do pensamento político moderno foi marcada pela tentativa de articular uma concepção de justiça que teria vigência e eficácia, antes de mais nada, nos limites de um tipo de sociedade específica, a saber: o Estado democrático. Se a prevalência dos direitos humanos é mencionada na Constituição de Estados democráticos modernos como uma referência ao modo como um Estado "se rege em suas relações internacionais", é porque o princípio da não-intervenção visa garantir que um Estado não irá violar os direitos humanos dos cidadãos de um outro Estado. Contudo, a questão sobre como um Estado deveria se comportar naquelas ocasiões em que os direitos humanos dos cidadãos de um outro Estado são sistematicamente violados pelo próprio Estado a que tais cidadãos pertencem recebeu, ao longo da tradição do pensamento político moderno, bem menos atenção. Com efeito, não poderia bem ser o caso de que, em algumas circunstâncias, pela prevalência mesma dos direitos humanos, um Estado tivesse a obrigação de intervir nos assuntos internos de um outro Estado?

No debate filosófico-político contemporâneo, tem havido um crescente interesse por esse tipo de questão, i.e., pelos princípios de justiça que deveriam ser observados no âmbito de uma sociedade global e sobre o modo como esses princípios se relacionam com o conceito de soberania nacional. Essa questão é fundamental, por exemplo, no exame acerca da legitimidade das denominadas "intervenções humanitárias". Intervenções humanitárias têm gerado grande controvérsia na comunidade internacional, tanto quando elas ocorrem, como na Somália (1992) e na Bósnia-Herzergovínia (1995), quanto quando elas deixam de ocorrer, como em Ruanda (1994). ${ }^{2}$ Quando elas ocorrem, há sempre a suspeita de que elas, em última instância, não decorrem da tentativa de se implementar alguma concepção de justiça no âmbito internacional, mas, antes, de se promover os interesses dos Estados interventores no Estado em cuja soberania se intervém. Quando, por outro lado, elas não ocorrem, critica-se como indiferente ou omissa a postura dos Estados em condição de impedir a sistemática violação dos direitos mais básicos de algum grupo de indivíduos. Intervenções humanitárias são controversas, porque elas envolvem um conflito entre dois tipos de violações: violação do princípio da não-intervenção, e violação de direitos humanos. Mas uma pergunta que podemos nos fazer, no contexto desse debate, é sobre até que ponto há realmente um con-

Cf. e.g., International Commission on Intervention and State Sovereignty, The Responsibility to Protect: Report of the International Commission on Intervention and State Sovereignty, 2002, p. vii. 
flito entre, de um lado, os interesses dos Estados, e, de outro lado, as exigências da moralidade.

O objetivo deste artigo é contribuir para o debate contemporâneo acerca do conceito de justiça internacional. Minha intenção é mostrar que, ao abordarmos esse problema, a partir de uma perspectiva contratualista, o conflito entre o denominado interesse nacional e as exigências da moralidade - conflito enfatizado sobretudo pelos representantes do realismo em relações internacionais - se mostra bem menos problemático. A tentativa de se articular uma concepção de justiça internacional, a partir de uma perspectiva contratualista, não é nova; ela remonta, como se sabe, a Kant, e tem contemporaneamente em Rawls seu principal representante. No entanto, como pretendo mostrar, o tipo de contratualismo defendido por Rawls e seus seguidores não é capaz de evitar as principais críticas feitas pelo realismo à tentativa de denfendermos uma concepção de justiça internacional. A meu ver, esse tipo de crítica só pode ser realmente evitado, se defendermos uma concepção de justiça internacional a partir do tipo de contratualismo defendido por autores como, por exemplo, David Gauthier e Peter Stemmer, mesmo considerando que esses autores, eles próprios, não buscam estender suas respectivas versões da idéia do contrato social ao âmbito da política internacional.

\section{II}

Uma atitude cética com relação à possibilidade de implementação de princípios de justiça; no âmbito das relações internacionais, é aquela tradicionalmente defendida pelo "realismo". Basicamente, a tese realista é que, na busca pela implementação de seus próprios interesses, o Estado não deveria delinear sua política externa à luz de considerações sobre princípios morais ou ideais de justiça. Numa palavra, como afirma Hans Morgenthau, um dos fundadores do realismo moderno em relações internacionais: "The actions of states are determined not by moral principles and legal commitments but by considerations of interest and power. ${ }^{\prime 3}$ Nesse sentido, o único compromisso moral que Estados nacionais deveriam assumir, no âmbito das relações internacionais, diria respeito, na melhor das hipóteses, à preservação da integridade de seus respectivos cidadãos, quando estes se encontrarem em circunstâncias perigosas fora de seus próprios territórios. Mas seria equivocado para um Estado, por outro lado, assumir obrigações morais para com a integridade dos cidadãos de um outro Estado. A tentativa de implementação de princípios morais em nível internacional poderia mesmo, alegam alguns autores realistas, terminar por colocar em risco a própria segurança interna e, conseqüentemente, ameaçar a implementação daqueles princípios morais e concepção de justiça sob os quais os cidadãos do Estado em questão desejam viver. Compreendido nesses termos, o realismo - se bem que, como veremos a seguir,

Citado em W. Thomas, The Ethics of Destruction: Norms and Force in International Relations, 2001, p. 5. Cf. também Morgenthau, Politics Among Nations: The Struggle for Power and Peace, 1973, p. 10: "... the state has no right to let its moral disapprobation get in way of successful political action, itself inspired by the moral principle of national survival." 
não apenas o realismo - pressupõe uma clara oposição entre, por um lado, a promoção do auto-interesse e, por outro lado, a implementação de princípios morais: ou bem estendemos a aplicação de princípios morais e ideais de justiça à esfera das relações internacionais e, com isso, abrimos mão da busca pela realização de certos interesses nacionais (interesses que, inclusive, quando se trata da manutenção da segurança nacional, serviriam para garantir o respeito aos princípios morais e ideais de justiça no interior do próprio Estado), ou restringimos o âmbito de aplicação de nossos princípios morais aos limites do Estado em que vivemos, empregando, com isso, o que Morgenthau denomina o "princípio moral da sobrevivência nacional". Para o realista, portanto, a intervenção na soberania de um outro Estado com vistas à implementação de princípios morais só se justificaria, quando o Estado, interventor tivesse no Estado, em cujos domínios a intervenção se realiza, interesses que não fossem estritamente morais. ${ }^{4}$

O que, no entanto, poderíamos nos perguntar é se o agir moral e a realização do auto-interesse de fato se excluem mutuamente nos termos sugeridos pelo realismo. Parece-me que o realismo em relações internacionais só pressupõe a validade dessa dicotomia porque, contemporaneamente, ele surge como uma reação ao "internacionalismo liberal", que vigorou na política internacional do período entre as duas Grandes Guerras. Um dos objetivos básicos dos representantes do "internacionalismo liberal" era a tentativa de aplicação de princípios políticos liberais no âmbito da política internacional. O que caracterizava então como "liberal" a política desse período era, em primeiro lugar, a idéia segundo a qual o princípio da rule of law, i.e., de um "estado de direito" em que ninguém estaria acima da lei, poderia ser aplicado tanto no plano doméstico quanto no plano internacional. A Liga das Nações surgiu nesse contexto justamente como uma tentativa de garantir a vigência do princípio da rule of law no âmbito da relação entre Estados. Em segundo lugar, a política do período entre-guerras era "liberal", no sentido de que ela assumia, de antemão, que haveria uma espécie de harmonia natural de interesses entre as nações. Conflitos de interesses - como aqueles que levaram à eclosão da Primeira Grande Guerra - deveriam ser compreendidos agora como resultantes de uma ignorância relativa aos "verdadeiros interesses" que as pessoas teriam, se elas pensassem e agissem em termos unicamente racionais. Chris Brown resume esse ponto nos seguintes termos:

The basic premise of virtually all this thought was that although it might sometimes appear that there were circumstances where interests clashed, in fact, once the real interests of the people were made manifest it would be clear that such circumstances were the product of distortions introduced either by the malice of special interests, or

4 Cf. e.g., C. Hauss, International Conflict Resolution: International Relations for the 21st Century, 2001, p. 58-59: "The focus on national interest also leads many realists to be skeptical about the kind of military involvement the United States and many other majors powers have engaged in since the end of the Cold War. [...] And while it is tempting for a state like the United States to want to intervene when another state or states is engaged in immoral or inhuman activity, as was the case in, for instance, former Yugoslavia and Rwanda, doing so does not make sense unless those critical interests are threatened." 
by simple ignorance. Thus, although liberal internationalists could hardly deny that in 1914 war was popular with the people, they could, and did, deny that this popularity was based on a rational appraisal of the situation. ${ }^{5}$

O internacionalismo liberal do período entre-guerras era representado, de fato, por autores bem diversos. ${ }^{6}$ Mas, ainda assim, ao analisarmos melhor os pressupostos teóricos da política externa desse período, o que percebemos é que as "premissas" do internacionalismo liberal eram essencialmente kantianas. Em primeiro lugar, porque a Liga das Nações foi fundada, como se sabe, a partir da idéia de uma Confederação de Estados inspirada no modelo sugerido por Kant na Paz Perpétua, de $1795 .^{7}$ Em segundo lugar, as premissas do internacionalismo liberal podem ser consideradas como kantianas, porque a idéia segundo a qual conflitos de interesses, quando racionalmente examinados, poderiam ser reinterpretados em termos de "interesses convergentes", envolve uma concepção não-instrumental de razão. É justamente uma tal concepção de razão que Kant emprega em sua teoria moral. A razão, nesse caso, não serviria para examinar os melhores meios a que deveríamos recorrer na busca pela realização dos interesses que de fato temos, mas para determinação mesma dos interesses que teríamos, se a razão fosse capaz de determinar sozinha nossa vontade. É somente porque, segundo Kant, a razão compartilha com as "inclinações" o poder de determinar nossa vontade que pode surgir para nós um conflito entre, por um lado, a satisfação de nossas inclinações, e, por outro lado, o agir moral, i.e., um agir motivado unicamente por respeito à lei moral. A dicotomia entre o auto-interesse (o auto-interesse é para Kant um tipo de inclinação) e o agir moral fica especialmente clara na distinção que Kant faz entre ações "por dever" (aus Pflicht) e ações meramente "conformes ao dever" (pflichtmäßig). ${ }^{8}$ Ações do segundo tipo, por mais desejáveis que sejam, não teriam propriamente qualquer valor moral. Elas seriam realizadas, não por respeito à lei moral, mas por força de alguma inclinação, como, por exemplo, o egoísmo, a vaidade, ou mesmo o altruísmo. É somente quando uma ação é realizada unicamente por respeito à lei moral, sem a influência de qualquer inclinação, que ela, segundo Kant, realmente adquire um valor moral.

O internacionalismo liberal assume como não-problemática essa distinção, e é por isso também que ele afirma haver algo como "os verdadeiros interesses" que os Estados teriam, se fossem inteiramente racionais em suas escolhas. Com efeito, segundo essa perspectiva, se Estados entram em conflito, é porque os interesses que têm são, pelo menos em parte, interesses não-racionais, interesses relativos à satisfação de alguma inclinação, por oposição aos seus "verdadeiros interesses",

Cf. e.g., Chris Brown, Understanding International Relations, 1997, p. 24. Cf. também Miles Kahler, "Inventing international relations: international relations theory after 1945", 1997, p. 20-53.

Ver e.g., D. Long e P. Wilson, Thinkers of the Twenty Years' Crisis, 1995

Cf. e.g., Georg Cavallar, "Kant's society of nations: free federation or world republic?", 1994, p. 461482. Cf. também Kevin Dodson, "Kant's Perpetual Peace: universal civil society or league of states?", 1993, p. 1-9.

8 Cf. Kant, Grundlegung zur Metaphysik der Sitten (Fundamentação da Metafísica dos Costumes, 1785), 1983, p. 22s. 
i.e., interesses que consistiriam em agir unicamente por respeito à lei moral. Conflitos de interesse, com outras palavras, envolveriam, segundo Kant, uma ignorância com relação a uma espécie de "interesse supremo" (das höchste Interesse), i.e. um interesse ao qual todos os outros interesses poderiam ser racionalmente subordinados. Esse "interesse supremo", segundo Kant, é determinado pela razão e consiste em uma "lei prática" que sempre seguiríamos, como afirma Kant: "Se a razão tivesse pleno domínio sobre nossa faculdade de desejar. ${ }^{\prime \prime}$ Certos interesses, portanto, seriam bons, tendo em vista tais e tais fins, mas apenas o interesse que temos na moralidade seria, segundo Kant, absolutamente e em si mesmo bom. Essa tese é claramente formulada em uma passagem da Crítica do Juízo (1790):

Aber, ungeachtet aller dieser Verschiedenheit zwischen dem Angenehmen und Guten, kommen beide doch darin überein: daß sie jederzeit mit einem Interesse an ihrem Gegenstand verbunden sind, nicht allein das Angenehme (§ 3), und das mittelbar Gute (das Nützliche), welches als Mittel zu irgend einer Annehmlichkeit gefällt, sondern auch das schlechterdings und in aller Absicht Gute, nämlich das moralische, welches das höchste Interesse bei sich führt. ${ }^{10}$

Nesse sentido, para Kant, conflitos de interesses poderiam sempre ser reinterpretados em termos de harmonia de interesses, contanto que pudéssemos racionalmente subordinar os interesses em jogo a um tipo de interesse que seria "absolutamente e em si mesmo bom". A moral para Kant não é, portanto, uma instituição socialmente constituída para a resolução de conflitos de interesses. Pelo contrário, ela não tenta solucionar conflitos de interesses, mas mostrar que certos interesses, por serem irracionais, não deveriam sequer surgir em primeira instância.

No entanto, podemos nos perguntar se a concepção de razão aqui em questão - razão compreendida como uma faculdade que, em seu uso prático, não apenas avaliaria os meios a que deveríamos recorrer, tendo em vista a implementação de tais e tais interesses, mas também de descobrir "o interesse supremo", absolutamente bom em si mesmo, e a que todos os outros interesses deveriam ser subordinados - pode ser de fato sustentada sem nos comprometermos com uma concepção metafísica de razão. Tal concepção de razão consiste, a meu ver, em uma espécie de invenção filosófica. Contudo, é justamente essa concepção de razão que foi endossada por diversos autores associados ao internacionalismo liberal do período entre-guerras, ao defenderem a tese segundo a qual conflitos de interesses envolveriam, em última instância, uma espécie de ignorância com relação aos "verdadeiros interesses" da humanidade. É bem verdade que essa reconstrução do argumento dos internacionalistas liberais não é aceita por todos. Antonio Franceschet, por exemplo, nega que Kant ter-se-ia se comprometido com a tese de inte-

$9 \quad$ Cf. Kant, op. cit., p. 27: "Maxime ist das subjektive Prinzip des Wollens; das objektive Prinzip (d.i. dasjenige, was allen vernünftigen Wesen auch subjektiv zum praktischen Prinzip dienen würde, wenn Vernunft volle Gewalt über das Begehrungsvermögen hätte) ist das praktische Gesetz."

${ }^{10}$ Kant, Kritik der Urteilskraft, 286, grifo meu. Cf. também Grundlegung zur Metaphysik der Sitten, p. 28: "Alles moralische so genannte Interesse besteht lediglich in der Achtung fürs Gesetz." 
resses "objetivamente harmoniosos". ${ }^{11}$ Contudo, parece-me que as evidências textuais proporcionadas pelos textos da Crítica do Juízo, e da Fundamentação da Metafísica dos Costumes, não mencionados por Franceschet, claramente mostram o quanto Kant de fato se comprometeu com a tese dos interesses "objetivamente harmoniosos". Ao criticarem como "utópica" e "idealista" a política internacional preconizada pelo internacionalismo liberal, o que autores realistas, como Morgenthau e E. H. Carr, tinham em mente não era a idéia segundo a qual seus predecessores compreendiam inadequadamente o problema da moral. O que interessava aos fundadores do realismo moderno era sublinhar os riscos envolvidos e a quase impossibilidade de abandonarmos o auto-interesse (ou "interesse nacional") em prol da moralidade. A concepção de moralidade subjacente ao internacionalismo liberal, ela própria, não é abandonada pelos autores realistas. Pelo contrário, o realismo assume que há, de fato, um conflito entre o auto-interesse e a moralidade. O que ele nega é que "fins mais nobres", como aquele representado pela moralidade, devessem ter algum tipo de precedência sobre questões de segurança nacional. ${ }^{12}$ Se o realismo em relações internacionais surge como uma reação ao internacionalismo liberal que vigorou no período entre guerras, isto não significa, por outro lado, que o realismo e o internacionalismo liberal não compartilhem uma mesma concepção de moral. O ponto de divergência entre eles era, antes de mais nada, sobre como conciliarmos os princípios da moralidade com as exigências da soberania nacional. Mas a concepção mesma de moral, endossada tanto por uns como pelos outros, não foi realmente colocada em questão.

Contudo, poderíamos nos perguntar se a própria concepção de moral em questão, tanto na posição realista, quanto na posição criticada pelos realistas, não seria essencialmente equivocada. O que pretendo mostrar aqui é que a moral e o auto-interesse, diferentemente do que tanto os internacionalistas liberais quanto os realistas assumem, não apenas não são incompatíveis, mas seria mesmo possível defendermos um tipo de teoria moral que derivasse princípios morais a partir da própria consideração de nossos interesses. Esta é, basicamente, a tese defendida hoje pelos representantes do contratualismo moral. Entre outros autores, destacam-se como representantes do contratualismo moral, por exemplo, Peter Stemmer e David Gauthier; este último, sobretudo, por influência de sua obra de 1986, intitulada Morals by Agreement.

\section{III}

Gauthier busca basicamente defender uma teoria do contrato social em que os princípios da moral seriam inteiramente extraídos de uma espécie de "contrato

11 Antonio Franceschet, "Sovereignty and freedom: Immanuel Kant's liberal internationalist "legacy'", 2001, p. 211, n. 9. Cf. também Hedley Bull, Anarchical Society: A Study of Order in World Politics, 1977, p. 24-6.

12 Cf. R. Gilpin, "The richness of the tradition of political realism", 1986, p. 305. "What characterizes realist thinking is the primacy in all political life of power and security in human motivation [...] what the realist seeks to stress is that these all more noble goals (beauty, truth, and goodness) will be lost unless one makes provisions for one's security in the power struggle." 
hipotético". A realização desse "contrato", no entanto, não decorreria da observação de certos princípios morais, pois, nesse caso, a moral já seria anterior ao contrato, não podendo, portanto, ser extraída do próprio contrato. A tese de Gauthier é que, em um contexto pré-moral, cada indivíduo buscaria maximizar suas preferências (promover o auto-interesse) sem qualquer tipo de restrição de ordem moral. Na teoria de Gauthier, esse contexto pré-moral corresponde exatamente àquilo que, no contexto da tradição de teorias do contrato social, se denomina "estado de natureza". Segundo Gauthier, no estado de natureza, ao buscarem promover o auto-interesse, sem qualquer tipo de restrição de ordem moral, os indivíduos se encontrariam em um tipo de situação comumente denominada em teoria dos jogos como "dilema dos prisioneiros". Nesse tipo de situação, dois indivíduos reconheceriam, por um lado, que a escolha mais racional para a maximização de suas respectivas preferências consistiria em participarem de um esquema de cooperação mútua. Por outro lado, devido à ausência de um mecanismo que garanta que ambos, de fato, cooperarão um com o outro, cada indivíduo acabaria por fazer um tipo de escolha que deixaria ambos em uma situação pior do que a situação a que chegariam, se cada um fizesse concessões para benefício do outro. ${ }^{13}$ Para Gauthier, a moral consiste justamente em uma instituição social que pode ser compreendida como um sistema de restrições mútuas criado para a superação do tipo de situação representada pelo dilema dos prisioneiros. A adesão aos princípios da moral implica, de fato, uma restrição voluntária de nossa própria liberdade, pois, ao aderirmos aos princípios da moral, abrimos mão da realização de certas ações que estaríamos, pelo menos em princípio, dispostos a realizar sem a adesão aos princípios. Mas a adesão aos princípios da moral, por outro lado, não implica renúncia à promoção de nossos interesses. Pelo contrário, compreendida nesses termos, a moral consiste em um sistema de restrições mútuas que, em última instância, viabilizaria a busca do auto-interesse. Se a concepção contratualista de moral defendida por Gauthier é correta, então a suposta oposição que os autores realistas alegam haver entre a promoção do auto-interesse e a observação dos princípios da moral se mostra infundada.

A defesa de uma teoria moral contratualista como um tipo de alternativa a outros tipos de teorias morais exigiria, por si só, uma discussão que fugiria ao escopo deste capítulo, que é propriamente o de tratar do conceito de justiça no âmbito das relações internacionais. Por essa razão, não vou me deter aqui nos detalhes do argumento desenvolvido pelos principais representantes do contratualismo moral, o que, evidentemente, não significa que a teoria moral contratualista seja imune a uma diversidade de objeções. ${ }^{14}$ Minha intenção é apontar para três objeções que

${ }^{13}$ Para uma discussão da relação entre o "dilema dos prisioneiros" e a idéia do "estado de natureza", ver Gauthier, The Logic of Leviathan: The Moral and Political Theory of Thomas Hobbes, 1967, p. 76-89. Cf. também Jean Hampton: "Modern social contracts theories", in Political Philosophy, 1998, p. 39-69.

14 Para uma exposição do contratualismo moral e das principais objeções que se podem fazer à teoria moral contratualista, ver, e.g., Stemmer "Moralischer Kontraktualismus", 2002. (Publicado em por- 
poderiam ser feitas por alguém que assumisse, pelo menos em princípio, que uma teoria moral contratualista pudesse ser defendida de modo plausível, mas que negasse que ela tivesse qualquer relevância no âmbito das relações internacionais. As objeções que tenho em mente levantam suspeitas, portanto, não sobre a plausibilidade de uma teoria moral contratualista enquanto tal, mas sobre a tentativa de justificarmos em bases contratualistas a adoção de princípios morais no âmbito da política internacional.

\section{IV}

Uma primeira objeção que se poderia fazer contra a tentativa de articularmos uma concepção de justiça internacional, a partir de uma perspectiva contratualista, é a seguinte: a pergunta pela possibilidade de compreendermos a dinâmica da relação entre Estados por meio da idéia de um contrato social não é nova. Ela remonta, como se sabe, a Hobbes, que nega, porém, ser possível estendermos à esfera da relação entre Estados a idéia de um contrato social. Em uma conhecida passagem do capítulo 13 do Leviathan, Hobbes assume, por um lado, que jamais houve de fato um "estado de natureza" entre indivíduos. Ele sustenta, no entanto, por outro lado, que a relação vigente entre os Estados reproduz as circunstâncias do "estado de natureza". Para Hobbes, portanto, a arena internacional seria como um "estado de natureza", porém não de indivíduos, mas de Estados em permanente conflito uns com os outros, na tentativa de garantirem a auto-preservação. Essa tese é defendida, não apenas no Leviathan, mas também em outras obras de Hobbes. Como ele afirma, por exemplo, no seu Dialogue: "You are not to expect such Peace between two Nations, because there is no Common Power in this World to punish their Injustice: mutual fear may keep them quiet for a time, but upon every visible advantge they will invade one another..."15 Desta forma, é justamente o argumento contratualista de Hobbes que, com freqüencia, é retomado para justificar a posição realista, segundo a qual a política externa dos Estados não deveria ser implementada sob a consideração de princípios morais ou concepções de justiça, pois isto poderia representar a ruína do próprio Estado. Com efeito, não há no âmbito da relação entre Estados um "poder comum" (Common Power), instituído por meio de um contrato, capaz de dirimir conflito de interesse entre eles. Com outras palavras, na medida em que os Estados não podem delegar a uma instância supra-estatal o poder de arbitrar sobre conflitos de interesse, sem que suas respectivas soberanias sejam ameaçadas, a relação vigente entre eles tem exatamente a mesma estrutura da relação que haveria entre indivíduos vivendo em um hipotético "estado de natureza".

tuguês em Ethica, "Contratualismo Moral", vol. 9, 2002, p. 203-226, trad. Marcelo de Araujo e Dário Alves Teixeira).

${ }_{15}$ A Dialogue between a Philosopher and a Student of the Common Laws of England, p. 57. Cf. também On the Citizen, p. 3-4: "There are two maxims which are surely both true: Man is a God to man, and Man is a wolf to Man. The former is true of the relations of citizens with each other, the latter of relations between commonwealths." 
Com relação a esta primeira objeção, temos de considerar que o contratualismo moral contemporâneo, diferentemente do tipo de contratualismo defendido por Hobbes, não envolve a idéia de uma instância superior. Com efeito, não existe, no âmbito da moral, um tipo de autoridade análoga à autoridade que o Estado exerce no âmbito da política doméstica. Assim, na teoria moral contratualista, não há um correspondente à figura hobbesiana do "soberano". E isso ocorre porque a moral, segundo Gauthier, não possui uma estrutura verticalizada: a não-adesão aos princípios da moral não vem necessariamente acompanhada - embora possa vir, a partir do momento em que os princípios da moral são incorporados nas normas de um sistema jurídico - de sanções impostas por algum tipo de instância superior. As sanções a que estamos submetidos, no caso da não-adesão aos princípios da moral, são, antes de mais nada, de caráter informal, e não de caráter legal: elas consistem, basicamente, nas desvantagens que experimentamos ao sermos alijados dos benefícios decorrentes da cooperação social. Para um indivíduo, que percebesse as vantagens da cooperação social como um veículo para efetivação de seu auto-interesse, seria mesmo racional desenvolver uma disposição para a cooperação, i.e., uma disposição para adotar de modo generalizado os princípios da moral. ${ }^{16}$ Com efeito, a teoria da escolha racional que Gauthier pressupõe no contexto de sua teoria moral é uma teoria acerca da escolha sobre disposições, e não sobre ações consideradas isoladamente. Como Gauthier afirma:

A choice is rational if and only if it maximizes the actor's expected utility. We identify rationality with utility-maximization at the level of dispositions to choose. A disposition is rational if and only if an actor holding it can expect his choices to yield no less utility than the choices he would make were he to hold any alternative disposition. ${ }^{17}$

Para Gauthier, assim como para outros representantes do contratualismo moral, é, portanto, importante que sejamos reconhecidos publicamente como indivíduos motivados para a realização de ações morais. A perda da reputação em contextos sociais pode resultar em uma exclusão das vantagens decorrentes da cooperação social. A mera exclusão, nesse caso, já pode ser considerada como um tipo de sanção. Embora de natureza informal, as sanções decorrentes da transgressão das normas da moral podem, em certas circunstâncias, até se mostrar bem mais severas ao transgressor do que aquelas sanções estabelecidas em termos jurídicos: ostracismo social e desprezo, por parte da comunidade em que vivemos, podem ser bem mais difíceis de suportar do que, por exemplo, o paga-

${ }^{16}$ Cf. e.g. Gauthier, Morals by Agreements, p. 162: "A person disposed to violate his covenants cannot be admitted as a party to co-operative arrangements by those who are both rational and aware of his disposition, and so such person cannot rationally expect to reap the benefits available to cooperators. Even if his particular breaches of covenant would benefit him, yet the disposition that leads him to such breaches does not." Cf. também Gauthier, Key Philosophers in Conversation, 1999, p. 133-134. A idéia segundo a qual Estados procuram manter sua reputação na comunidade internacional é examinada, e.g., por Cristina Bicchieri, "Reputation", in Rationality and Coordination, p. 188-192.

17 Cf. Morals by Agreement, p. 182-183. 
mento de multas ou a perda temporária da liberdade. ${ }^{18}$ Mas será que as "sanções informais" que a moral exerce sobre os indivíduos, no contexto de comunidades específicas, teriam o mesmo efeito coercitivo quando pensamos, não em indivíduos, mas em Estados interagindo entre si no contexto bem mais amplo de uma comunidade de Estados? Esta questão está relacionada à segunda objeção que se poderia fazer contra a idéia de um contrato social no âmbito das relações internacionais.

\section{$\mathbf{V}$}

Uma segunda razão para suspeitarmos da plausibilidade da tentativa de justificarmos em bases contratualistas a adoção de princípios morais, no âmbito da relação entre Estados, decorre, justamente, do fato de podermos nos perguntar se podemos sancionar moralmente Estados da mesma forma que sancionamos moralmente indivíduos. Com outras palavras, poderíamos nos perguntar se apenas indivíduos, interagindo no contexto de comunidades específicas, podem se ver submetidos a sanções informais, ou se as próprias comunidades poderiam estar igualmente submetidas a sanções dessa natureza, no contexto bem mais amplo de uma comunidade de comunidades ou, para sermos mais precisos, no contexto bem mais amplo de uma comunidade internacional. A suposição de que comunidades, tal como indivíduos, podem ser moralmente sancionadas, poderia em princípio parecer equivocada, se assumíssemos, de antemão, que uma comunidade, enquanto tal, só existe, na medida em que possamos reconhecer nela uma instância superior capaz de arbitrar quanto a conflitos de interesses e de sancionar os transgressores das normas que ela própria - a instância superior - estabelece. Se a existência de uma instância superior é uma condição para falarmos da existência de uma comunidade, então seria certamente equivocado falarmos da existência de uma comunidade internacional, pois o que falta no âmbito das relações internacionais é justamente a existência de tal instância superior.

Contudo, podemos negar que o conceito de comunidade envolva dessa maneira o conceito de uma instância superior. Com efeito, podemos considerar que, em uma dada comunidade, a instituição responsável pela resolução de conflitos de interesses e imposição de sanções não diga essencialmente respeito a uma instância superior, mas, antes, a uma mera coordenação de interesses. É nesse sentido que, por exemplo, Palmerston, em meados do século 19, já se refere à "balança de poder" como uma espécie de instituição que, no âmbito da "comunidade de nações", compeliria os Estados mais poderosos a "respeitar" a independência de seus vizinhos menos poderosos. Como ele afirma:

[...] it is to the interest of the community of nations that no nation should acquire such a preponderance as to endanger the security of the rest; and it is for the advantage of

Cf. Peter Stemmer, Handeln zugunsten anderer: Eine moralphilosophische Untersuchung, 2000, p. 73s. Cf. também J. L. Mackie, Ethics: Inventing Right and Wrong, 1977, p. 117: "The stigma of cowardice, with the disgrace and shame associated with it, can be as effective as external penalties." 
all that the smaller Powers should be respected in their independence and not swallowed up by their more powerful neighbours. That is the doctrine of the balance of power, and it is a doctrine worthy of being acted upon. ${ }^{19}$

É desnecessário dizer que, para Palmerston, os Estados não entram em um acordo para criarem a "balança de poder", pois esta surge espontaneamente de uma simples coordenação de interesses. O que importa para falarmos aqui de uma "comunidade de nações" não é, portanto, a existência de uma instância superior de caráter supranacional, mas uma instituição - segundo Palmerston a "balança de poder" - que decorre da coexistência mesma dos Estados.

O conceito de "comunidade de nações" ou, para sermos mais precisos, de "sociedade internacional" foi retomado e sistematizado na segunda metade do século vinte, no contexto da denominada Escola Inglesa de teorias sobre relações internacionais. A Escola Inglesa, representada sobretudo por autores como Martin Wight, Hedley Bull, Barry Buzan, entre outros, reconhece a relevância da tese realista segundo a qual Estados nacionais coexistem em um mundo "anárquico", no sentido de que os Estados nacionais não estão subordinados a uma instância superior, capaz de lhes ditar normas e impor sanções, caso ocorra a violação dessas mesmas normas. A Escola Inglesa nega, no entanto, a idéia segundo a qual, na ausência de um órgão regulador de âmbito internacional, caberia aos Estados unicamente zelar pela auto-preservação. É nesse sentido que os autores ligados à Escola Inglesa defendem uma teoria acerca da "sociedade internacional". Em The Anarchical Society: A Study of Order in World Politics (1977), Bull procura mostrar, contra o realismo, ser possível falarmos em uma "sociedade internacional", mesmo admitindo a inexistência de uma instância superior de caráter supranacional. Isto, no entanto, não significa comprometer-se com a tese idealista endossada pelos representantes do internacionalismo liberal segundo a qual haveria, no âmbito da relação entre Estados, uma convergência natural de interesses. Com efeito, Bull admite que a arena internacional é caracterizada pelo conflito de interesses. Contudo, ele sustenta também que, ainda assim, seria possível pensarmos a anarquia predominante na arena internacional, não como um estado de natureza hobbesiano de guerra de todos contra todos, mas como um âmbito em que teriam eficácia certas sanções informais como, por exemplo, aquelas decorrentes da tentativa de se desequilibrar a balança de poder. ${ }^{20} \mathrm{~A}$ balança de poder representaria, assim, um tipo de instituição não-estatal que, de alguma forma, serviria para regular a relação entre Estados. Além da balança de poder, Bull menciona ainda como outras instituições dessa natureza, por exemplo, a diplomacia e o comércio. O oposto da anarquia, nesse sentido, não é a ordem, mas o governo: pode haver ordem, mesmo onde não há um governo constituído em torno de algum tipo de autoridade política central.

19 Lord Palmerston, "The balance of power defended" (1864), p. 444, grifo meu.

${ }^{20}$ Cf. Hedely Bull, "The balance of power and international order", in The Anarchical Society: A Study of Order in World Politics, 1977, p. 101-126. Ver também Martin Wight, "The balance of power", 1995, p. 168-185. 
É bem verdade que se poderia alegar que a cooperação internacional, compreendida nesses termos, seria motivada apenas pelo auto-interesse. Se os Estados aderem a certas instituições como as da balança de poder, do comércio, e da diplomacia, "respeitando", por exemplo, a independência de seus vizinhos menos poderosos, não é porque o "respeito" se impõe como moralmente necessário, mas porque - para empregar a expressão de Palmerston - é mais "vantajoso" para todos os Estados procederem dessa forma. Mas as vantagens decorrentes do respeito aos Estados menos poderosos - continua a objeção - nada tem a ver com a moralidade; o respeito, nesse caso, não teria propriamente um valor moral, porque os Estados mais poderosos se veriam menos compelidos a agirem desta forma, caso o respeito aos Estados menos poderosos não resultasse em algum tipo de vantagem. Essa objeção, no entanto, não me parece justificada, e a razão para isso já foi esclarecida anteriormente: essa objeção assume que uma ação só é moral (seja o sujeito da ação um indivíduo ou o Estado como um todo), se ela não decorrer de considerações sobre a efetivação do auto-interesse. No entanto, é precisamente essa tese que o contratualismo moral nega. Para o contratualismo, a moralidade é um tipo de instituição social criada com o fim de atender nossos próprios interesses. Aderir à moral, nesse sentido, significa aderir a um sistema de "maximização restrita" de nossos próprios interesses. Como afirma Gauthier: "Our claim is that in certain situations involving interaction with others, an individual chooses rationally only in so far as he constrains his pursuit of his own interest or advantage to conform principles expressing the impartiality characteristic of morality. To choose rationally, one must choose morally. ${ }^{212}$ Se isto é assim, então o debate contemporâneo acerca, por exemplo, da legitimidade das denominadas intervenções humanitárias não deveria se concentrar na pergunta sobre se são ou não "genuinamente morais" os interesses que levam um grupo de Estados a intervir na soberania de um Estado em cujas fronteiras esteja sendo perpetrada uma sistemática violação dos direitos humanos. Isso não significa, evidentemente, que esta pergunta não deva ser colocada. Mas ela, de todo modo, não deveria constituir sozinha o critério por meio do qual avaliaríamos a legitimidade ou não de uma intervenção por razões humanitárias. Como salienta Simon Caney:

Policies motivated to some extent by the national interest may also have beneficial outcomes for others. Furthermore, states might acquire prestige and standing through humanitarian acts. A political leader might, for example, seek to enhance his or her reputation through securing policy success (such as facilitating peace in Middle East). ${ }^{22}$

Na discussão acerca dos problemas políticos e morais que as denominadas intervenções humanitárias envolvem, não é necessário assumirmos, de antemão, que a promoção do auto-interesse no âmbito da relação entre Estados entre necessariamente em conflito com os princípios da moralidade expressos nos ideais

Gauthier, Morals by Agreement, p. 4.

2 Simon Caney, "Humanitarian intervention and state sovereignty", 2000, p. 126. 
de proteção aos direitos humanos, uma vez que é possível articularmos uma concepção de moralidade em que os princípios de imparcialidade, próprios da moral, sejam estabelecidos pela consideração mesma do auto-interesse. Contudo, poderia ser levantada agora uma terceira objeção a uma teoria do contrato social de âmbito internacional: um contrato social no âmbito internacional, nos termos sugeridos aqui, seria inexeqüível, pois os Estados, sendo extremamente desiguais entre si, no que se refere, por exemplo, à capacidade tecnológica, poderio bélico, e desenvolvimento econômico, dificilmente participariam de um contrato para o estabelecimento de princípios de justiça de âmbito internacional movidos unicamente pela busca da maximização restrita do auto-interesse. Com efeito, em um contexto de desigualdade, e sem a assunção prévia de uma determinada concepção de justiça, não seria do interesse dos Estados mais fortes fazer um contrato com os mais fracos com vistas ao estabelecimento, por exemplo, de um princípio de nãoagressão mútua. Com outras palavras, na ausência de uma relativa igualdade, os Estados não participariam de um hipotético contrato para o estabelecimento de princípios de justiça.

Uma maneira de lidarmos com essa objeção seria negarmos que a única possibilidade de articularmos uma teoria do contrato social em âmbito internacional dependa de considerações sobre quais princípios de justiça seriam estabelecidos por agentes movidos unicamente pelo auto-interesse. Esta é, como se sabe, a posição defendida por John Rawls em The Law of Peoples (1999). Essa obra constitui, de fato, uma das mais recentes tentativas sistemáticas de se investigar questões normativas de política internacional a partir de uma perspectiva contratualista. Contudo, não me parece que nem Rawls nem seus seguidores apresentem uma resposta satisfatória ao problema que o fato das enormes desigualdades vigentes no cenário internacional representa para uma teoria do contrato social de âmbito internacional. A meu ver, como pretendo mostrar a seguir, o tipo de contratualismo defendido por Gauthier, bem como por outros representantes contemporâneos do contratualismo moral, é capaz de oferecer uma resposta mais satisfatória para este problema.

\section{VI}

Até aqui referi-me à idéia de um contrato social no âmbito da relação entre Estados, tendo principalmente em vista o tipo de contratualismo defendido por Gauthier. No entanto, é importante notarmos que Gauthier, ele próprio, não procura estender sua teoria a questões de ordem moral que surgem no exame da política internacional. Na verdade, a teoria de Gauthier é, antes de mais nada, uma teoria moral, e não uma teoria política, i.e., um tipo de investigação acerca dos princípios políticos em torno dos quais deveríamos organizar a nossa vida social. A mais conhecida teoria contratualista contemporânea que tem justamente por ambição responder a questões de ordem política é, como se sabe, aquela desenvolvida por Rawls em A Theory of Justice (1971). A teoria política de Rawls se insere na tradição do contrato social, na medida em que, em A Theory of Justice, Rawls se pergunta sobre os princípios que os indivíduos na "posição original", por 
trás de um "véu de ignorância", escolheriam para a organização da vida em sociedade. ${ }^{23}$ A própria idéia de uma "posição original" é, basicamente, apenas uma outra designação para o que, na tradição do contrato social, se denomina comumente de "estado de natureza". Contudo, embora tanto Rawls quanto Gauthier sejam importantes representantes contemporâneos da tradição do contrato social, há, entre suas respectivas versões do contratualismo, algumas diferenças fundamentais. Gauthier se pergunta sobre como poderíamos justificar o agir moral a partir de razões que não fossem elas próprias morais. Com outras palavras, Gauthier se pergunta sobre a estrutura da moralidade deixando, porém, em aberto a pergunta quanto ao tipo de instituição política em que os princípios de imparcialidade típicos da moralidade poderiam ser melhor exercidos. Rawls, por outro lado, não busca fundamentar a moral a partir de premissas não-morais. Pelo contrário, ele assume que na posição original os indivíduos já partilhariam um "senso de justiça" (sense of justice) como fairness e que fariam um acordo, sob o véu da ignorância, para a criação de uma instituição política no contexto da qual esse "senso de justiça" pudesse ser efetivamente exercido. Esse senso de justiça, segundo Rawls, não seria socialmente constituído, mas representaria, antes, um "aspecto fundamental do self". ${ }^{24}$ Gauthier exprime nos seguintes termos o modo como sua própria versão da teoria do contrato social se diferencia da teoria de Rawls.

Rawls' idea, that principles of justice are the objects of a rational choice, is indeed one that we shall incorporate into our own theory, although we shall represent the choice as bargain, or agreement, among persons who need not be unaware of their identities. But this parallel between our theory and Rawls's must not obscure the basic difference; we claim to generate morality as a set of rational principles of choice. We are committed to showing why an individual, reasoning from non-moral principles, would accept the constraints of morality on his choices. ${ }^{25}$

É importante notarmos agora que, se Rawls, por um lado, diferentemente de Gauthier, se pergunta pela configuração própria do tipo de instituição política em que os princípios de justiça extraídos do contrato social se exerceriam, por outro lado, o tipo de instituição política que ele tem aqui em mente é bastante específiCo, a saber: o Estado democrático liberal moderno. Na obra de 1971, Rawls deixa explicitamente de lado a pergunta pelo modo como princípios de justiça poderiam ser aplicados, também, no âmbito mais amplo de instituições internacionais. Como ele próprio afirma, logo no início de sua obra: "I shall not consider the justice of institutions and social practices generally, nor except in passing the justice of

${ }^{23}$ O comprometimento de Rawls com a tradição do contrato social é atestado já no início de A Theory of Justice, p. xviii: "What I have attempted to do is to generalize and carry to a higher order of abstraction the traditional theory of the social contract as represented by Locke, Rousseau, and Kant." Rawls, A Theory of Justice, p. 493.

25 Morals by Agreement, p. 5. Cf. também Gauthier, "Between Hobbes and Rawls", 1993, p. 31: "Hobbes, unlike Rawls, seeks to derive justice from the rational agreement of persons who have no prior moral concerns, and who view preservation as fundamental, not moral personality." 
the law of nations and of relations between states. ${ }^{\text {26 }}$ Contudo, a obra de Rawls teve tal influência sobre o debate filosófico-político contemporâneo que diversos autores tentaram estender de modo sistemático os elementos centrais da teoria da justiça desenvolvida em A Theory of Justice a questões de política internacional. Nesse sentido, destacam-se, por exemplo, os trabalhos de Charles Beitz, Thomas Pogge e Joe Carens. A despeito das distinções que há entre suas respectivas versões da idéia de um contrato social de âmbito internacional, a partir de uma perspectiva rawlsiana, esses autores recorrem à idéia de uma posição original, não para se perguntarem sobre os princípios de justiça que os futuros cidadãos de uma comunidade política específica escolheriam sob o véu da ignorância, mas que princípios de justiça qualquer ser humano, nas mesmas condições e, portanto, ignorante também de sua própria nacionalidade, escolheria. Os princípios de justiça, nesse caso, diriam respeito aos direitos e obrigações que os indivíduos teriam, não na qualidade de cidadão deste ou daquele Estado, mas enquanto seres humanos. O que está aqui em questão, como se pode ver, é uma concepção "cosmopolita" de cidadania, na medida em que cada indivíduo poderia se reconhecer, independentemente de sua filiação a este ou àquele Estado, como uma espécie de "cidadão do mundo". ${ }^{27}$ Assim, esta abordagem tem como pretensão justificar um conjunto de direitos fundamentais que, por exemplo, refugiados, imigrantes, ou exilados teriam, ainda que os Estados de que provêm não estejam mais em condição, ou se recusem a lhes garantir certos direitos fundamentais que os cidadãos de qualquer Estado democrático devem poder usufruir. ${ }^{28}$

No entanto, embora uma concepção cosmopolita de cidadania pudesse parecer a conseqüência natural da teoria da justiça de Rawls, quando aplicada à arena internacional, o interessante é que Rawls, ele próprio, em The Law of Peoples, não chega às mesmas conclusões a que seus seguidores chegaram entre o final da década de setenta e o início da década de noventa. Com efeito, ao examinar em bases contratualistas o problema da justiça no âmbito internacional, Rawls, para surpresa (ou talvez decepção) de seus seguidores, não defende uma concepção cosmopolita de cidadania. ${ }^{29} \mathrm{E}$ a razão para isso é que, segundo Rawls, os protagonistas da posição original não seriam os seres humanos de modo geral, mas Estados, ou melhor, representantes de "povos" (peoples). ${ }^{30}$ Rawls faz uma distinção

A Theory of Justice, p. 7. Cf. também p. 331-335

Cf. e.g. Leif Weinar, "The legitimacy of peoples", 2002, p. 55: "Beitz and Pogge proposed a cosmopolitan reformulation of domestic justice as fairness, which takes as its protagonists not citizens of a liberal society but instead all human being regarded as "citizens of the world'."

28 Cf. Seyla Benhabib, "Transformations of Citizenship: Dilemmas of the Nation State in the Era of Globalization", 2001, p. 39: "[Joe] Carens uses the device of the Rawlsian 'veil of ignorance', against the intentions of Rawls himself, to think through principles of justice from the standpoint of the refugee, the immigrant, and the asylum seeker."

29 Cf. The Law of Peoples, p. 82 para a crítica de Rawls a Pogge, Beitz e outros autores que buscaram extrair uma concepção cosmopolita de cidadania a partir da teoria do contrato social discutida em A Theory of Justice.

30 Ibid., p. 27: 'The term 'peoples', then, is meant to emphasize these singular features of peoples as distincts from states, as traditionally conceived, and to highlight their moral character and the reasonably just, or decent, nature of their regimes." 
entre Estados e povos, porque, para ele, apenas povos poderiam ser concebidos como integralmente comprometidos com o respeito a outros povos em bases igualitárias. ${ }^{31}$ Isso não significa, porém, identificar o conceito de "povo" com o conceito de "Estado democrático liberal". Há certamente sociedades que, segundo Rawls, sem serem democracias liberais do ponto de vista de suas respectivas políticas domésticas, são suficientemente "decentes" para, no âmbito da política externa, respeitarem outros povos em bases igualitárias. ${ }^{32}$ Dessa forma, assim como os indivíduos na posição original já partilhariam de um senso de justiça, na posição original com vistas ao estabelecimento de um empreendimento cooperativo de âmbito internacional "on fair terms" os povos já se compreenderiam como morais. ${ }^{33}$ Por essa razão, os participantes do tipo de contrato social que Rawls descreve nesse contexto se "respeitariam" por razões diferentes daquelas razões que, segundo Palmerston, levariam os Estados a se respeitarem uns aos outros. Com efeito, a razão para o respeito mútuo aqui não decorre da constatação das desvantagens decorrentes da não-cooperação com os demais participantes do contrato, mas do fato de os participantes, definidos nos termos sugeridos por Rawls, i.e., como povos, e não como Estados, já se compreenderem como morais. É por serem morais, então, que eles "honrarão os termos" do contrato, ainda que, em circunstâncias particulares, eles tenham mais a ganhar violando esses mesmos termos. Como Rawls afirma:

It is, therefore, part of a people's being reasonable and rational that they are ready to offer to other peoples fair terms of political and social cooperation. These fair terms are those that a people sincerely believes other equal peoples might accept also; and should they do so, a people will honor the terms it has proposed even in those cases where that people might profit by violating them. ${ }^{34}$

É desnecessário dizer que, a partir dessa perspectiva, a objeção a que me referi, ao final da seção anterior, sequer se coloca: superioridade de ordem tecnológica, econômica, e bélica não apenas não demoveriam os Estados (ou povos) de participarem de um "contrato social", como também não os levariam a abandonar os termos deste contrato tão logo esta se apresentasse como a opção mais vantajosa. E isso é assim, porque, segundo Rawls, os participantes do contrato, sendo povos, por oposição a Estados, já se compreenderiam como comprometidos com o ideal de respeito mútuo em bases igualitárias. Mas não me parece, no entanto, que a distinção, a meu ver problemática, entre Estados e povos resolva de modo adequado o problema que as enormes desigualdades predominantes na esfera internacional representam para uma teoria do contrato social no âmbito das rela-

${ }^{31}$ Ibid., p. 35: "What distinguishes peoples from states - and this is crucial - is that just peoples are fully prepared to grant the very same proper respect and recognition to other peoples as equals."

32 Ibid., p. 3, 83 et passim.

${ }_{33}$ Ibid., p. 25: "As reasonable citizens in domestic society offer to cooperate on fair terms with other citizens, so (reasonable) liberal (or decent) peoples offer fair terms of cooperation to other peoples. A people will honor these terms when assured that other peoples will do so as well."

${ }^{34}$ Ibid., p. 35 
ções internacionais. E esse problema também não se resolve, quando concebemos os participantes do contrato, tal como propuseram os seguidores de Rawls, como seres humanos de modo geral, independentemente de seus respectivos vínculos a este ou àquele Estado. Vejamos primeiramente o problema que o tipo de contratualismo cosmopolita desenvolvido por alguns dos seguidores de Rawls envolve.

Contra uma concepção cosmopolita de cidadania, fundada em bases contratualistas, o que se pode basicamente alegar é que ela não explica satisfatoriamente que tipo de instituição política garantiria o respeito aos direitos de qualquer "cidadão do mundo". Este problema não ocorre, evidentemente, quando temos em mente o tipo de contratualismo em questão em A Theory of Justice, pois, nesse caso, o que está em questão é justamente a criação de uma instituição no contexto da qual os princípios de justiça estabelecidos na posição original pudessem ser exercidos. Com efeito, no contexto de Estados democráticos, existem instituições responsáveis pela imposição de penalidade diversas contra aqueles que violam os princípios de justiça estabelecidos na posição original. Contudo, a estrutura de instituições dessa natureza não é adequadamente esclarecida no contexto do contratualismo cosmopolita defendido por Pogge, Beitz e outros seguidores de Rawls. ${ }^{35}$ Em The Law of Peoples, por outro lado, Rawls procura esclarecer qual tipo de instituição política emergiria de uma aplicação da idéia do contrato social em termos internacionais. Mas o tipo de instituição política que Rawls tem em mente, nesse caso, ao contrário do que se poderia talvez esperar, não diz respeito a nenhum tipo de instância superior aos próprios participantes do contrato. O que está em questão, ao longo de sua obra de 1999, é uma discussão sobre a "política externa" (foreign policy) que os "povos" razoavelmente justos e liberais deveriam adotar. Como afirma Rawls: "The Law of Peoples proceeds from international political world as we see it, and concerns what the foreign policy of a reasonably just liberal people should be. ${ }^{, 36}$ Dessa forma, os povos poderiam legitimamente prever em suas respectivas políticas externas medidas retaliativas a "Estados fora da lei" (outlaw states), intervindo em seus assuntos domésticos, por exemplo, em casos graves de violação de direitos humanos. ${ }^{37}$ Um Estado fora da lei, nesse sentido, não seria um Estado que se recusasse a agir em conformidade com princípios de justiça que ele próprio, na posição original, tivesse estabelecido com outros Esta-

${ }^{35}$ Cf. e.g. Christine Chwaszcza, "Anmerkungen zur vertragstheoretischen Begründung globaler Gerechtigkeit", 1997, p. 213: "Die kosmopolitische Konzeption globaler Gerechtigkeit hat jedoch einen entscheidenden Nachteil: Sie führt, will man nicht die Errichtung eines Weltstaates fordern, zur Ablösung der Gerechtigkeit von politischen Institutionen und hebt somit die Differenzierung zwischen politischen und moralischen Rechten und Pflichten auf." Cf. também Amartya Sen, "Justice across borders", 2002, p. 40: "There are great difficulties in trying to apply this <SC. Rawlsian analysis $>$ mode of reasoning to the whole of humanity, without an adequately comprehensive institutional base that can serve to implement the rules hypothetically arrived at in the original position for the entire world."

${ }^{36}$ The Law of Peoples, p. 83. Cf. também ibid. p 10: "I emphasize that, in developing the Law of Peoples within a liberal conception of justice, we work out the ideals and principles of the foreign policy of a reasonably just liberal people. This concern with the foreign policy of a liberal people is implicit throughout."

37 Ibid., p. 80-1. 
dos. Pelo contrário, tal Estado sequer participaria da posição original, e ele é sancionado, antes de mais nada, na expectativa de que possa vir a ser integrado na comunidade dos povos. ${ }^{38}$ Assim, a teoria de Rawls resolve o problema que as enormes desigualdades predominantes no cenário internacional representam prima facie para a idéia de um contrato social de âmbito internacional negando que este seja realmente um problema. Esse problema não surge para Rawls, porque os participantes do contrato, já se compreendendo como morais, não se valeriam de vantagens econômicas, tecnológicas, e bélicas sobre outros participantes do contrato; e os Estados que, por outro lado, estivessem dispostos a se beneficiar de outros Estados, por força de vantagens dessa natureza, são de antemão excluídos da posição original. Se um Estado recorrer à superioridade de ordem econômica, tecnológica, ou bélica como uma justificativa para não participar "on fair terms" com outros Estados de um empreendimento cooperativo, então, segundo Rawls, este Estado, a rigor, não poderia ser admitido na comunidade dos povos; sua política externa não seria a política externa de um povo decente. Nesse sentido, a teoria de Rawls retoma sem maiores qualificações as teses centrais do "internacionalismo liberal" a que me referi no início do presente artigo, sem, de fato, levar em consideração toda uma tradição realista de críticas a esta mesma posição. Na verdade, Rawls, ele próprio, admite seguir em The Law of Peoples as linhas gerais do projeto descrito por Kant em A Paz Perpétua. ${ }^{39}$ E como vimos há pouco, é justamente este projeto que, a partir da segunda metade do século vinte, começa a ser criticado como "idealista" e "utópico" por realistas como Morgenthau e Carr. ${ }^{40}$

A concepção de contrato social de âmbito internacional que defendo aqui evita, tanto os problemas que a posição de Rawls, quanto os problemas que a concepção cosmopolita de justiça envolvem. A concepção que tenho em mente aqui se distingue das teorias de Rawls e de seus seguidores em dois pontos fundamentais: (i) em primeiro lugar, não é necessário supormos que os participantes do contrato compartilhem, previamente ao contrato, de um senso de justiça; (ii) em segundo lugar - e este é o ponto mais importante - os participantes do contrato não são indivíduos, mas Estados e grupos de interesse. Por grupos de interesse entendo grupos sociais de naturezas diversas que se identificam em torno de interesses específicos e que podem interagir entre si em escala global com outros grupos de interesse e também com Estados.

${ }^{38}$ Cf. e.g., Leif Weinar, op. cit., p. 64: "When a Rawlsian people intervenes in another's people affairs, to stop human rights abuses or to provide food aid, the intervention is not for the sake of the wellbeing of the opressed or the starving individuals in the country. Rather, the intervenor aims at bringing the 'outlaw' or 'burdened' people up to the level of legitimacy, so that it can play its role in the society of people."

${ }^{39}$ The Law of Peoples, p. 10: "The basic idea is to follow Kant's lead as sketched by him in Perpetual Peace (1795) and his idea of foedus pacificum. I interpret this idea to mean that we are to begin with the social contract idea of the liberal political conception of a constitutionally democratic regime and then extend it by introducing a second original position at the second level, so to speak, in which the representatives of liberal peoples make an agreement with other liberal peoples".

40 A primeira seção de The Law of People tem o signficativo título: "The Law of Peoples as Realistic Utopia". 
Desde aproximadamente o início da década de noventa tem havido um número crescente de publicações que buscam chamar atenção para o fato de os atores da política mundial não serem mais apenas os Estados. E mesmo assumindo-se que os Estados continuem sendo os principais atores no plano internacional - o que por si já constitui uma tese controversa - há um reconhecimento de que, cada vez mais, os Estados têm de interagir com uma diversidade de grupos de interesse, tais como: organizações não-governamentais de caráter doméstico e internacional; grandes corporações com faturamentos por vezes superior ao PIB de alguns Estados; grupos de proteção ao meio ambiente, como, por exemplo, Greenpeace e Women's Enviromental Network; entidades humanitárias, como Human Rights Watch, Médecins sans Frontières, Amnesty International, Red Cross, e Oxfam International; grandes agências de notícias como Reuters e CNN; e mesmo grupos terroristas e outras entidades criminosas com ramificações em diferentes partes do planeta. ${ }^{41}$ Nesse sentido, a própria palavra "internacional", empregada pela primeira vez por Jeremy Bentham, no século 18, tem parecido a muitos autores pouco adequada para designar indiscriminadamente os diversos modos de relacionamento que passaram a se estabelecer no âmbito da política mundial, sobretudo a partir da segunda metade do século vinte. Com efeito, a relação entre nações diz respeito apenas a um tipo de relação vigente no cenário político mundial. Por essa razão, expressões como "justiça global", "política transnacional", ou "comunidade política planetária" têm sido freqüentemente empregadas em lugar de expressões em que ocorre a palavra internacional, de modo a evitar reduzir-se a discussão sobre questões políticas e morais de caráter "global", "transnacional" ou "planetário" ao domínio estrito da relação entre Estados nacionais. De todo modo, emprego a palavra "internacional", neste capítulo, para me referir, de modo geral, às relações que se estabelecem (i) entre Estados, (ii) entre diferentes grupos de interesse de âmbito global, bem como (iii) entre Estados e grupos de interesse.

O processo de globalização, nas últimas décadas, tem contribuído para que diversos grupos de interesse possam ser caracterizados como atores da política internacional, porque, cada vez mais, de modo direto ou indireto, eles entram num processo de barganha com Estados, em questões, por exemplo, de ordem política, econômica, humanitária, ou ecológica. É desnecessário dizer que um mesmo indivíduo não precisa se reconhecer como representante de um único grupo de interesse. Uma mulher, por exemplo, pode se identificar como cidadã brasileira, ativista da Amnesty International, e defensora de causas ecológicas promovidas pelo Greenpeace. Com outras palavras, nossa afiliação a um Estado nacional não é, como vários autores têm buscado contemporaneamente enfatizar, o único modo

${ }^{41}$ Cf. e.g., Peter Willetts, "Transnational actors and international organizations in global politics", 2001, p. 357. Cf. também (orgs.) M. Grene Lyons e Michael Mastanduno, Beyond Westphalia? State Sovereignty and International Intervention, 1995. 
através do qual articulamos nossa própria identidade. ${ }^{42}$ Pelo contrário, na medida em que, no contexto de Estados democráticos liberais, o direito de livre associação é reconhecido como um direito fundamental, através do qual expressamos publicamente nossa própria identidade, podemos legitimamente nos associar a um grupo de âmbito internacional que entre em conflito com os interesses do próprio Estado ao qual pertencemos. Esse tipo de fenômeno, como nota Seyla Benhabib, tem de fato ocorrido cada vez mais freqüentemente nas últimas décadas. ${ }^{43}$ Dessa forma, grupos de interesse podem ser compreendidos como tipos de associações voluntárias que podem ter um caráter meramente doméstico, atuando no âmbito da sociedade civil, como também podem assumir um caráter internacional, atuando no âmbito mais amplo do que vários autores já têm denominado uma "sociedade civil global". ${ }^{44}$ Tanto em um caso como no outro grupos de interesse podem ser considerados como atores com os quais os Estados têm de interagir num processo de barganha que envolve, freqüentemente, concessões, por parte de todos os envolvidos. Grupos de interesse, portanto, e não apenas Estados, podem ser vistos como participantes de um contrato social no contexto do qual seriam articulados princípios de justiça de âmbito internacional. Evidentemente, não é necessário supormos que todos os participantes desse contrato já se reconheçam como morais - ou "decentes", para empregar aqui o vocabulário de Rawls. Cada participante pode ser compreendido como comprometido, antes de mais nada, com a maximização do seu próprio interesse. Contudo, como Gauthier procura mostrar, no contexto de sua teoria moral, a maximização irrestrita do próprio interesse deixaria todos os participantes em uma posição pior do que a posição a que chegariam, se empregassem uma estratégia de maximização restrita do próprio interesse. Buscar maximizar o próprio interesse de modo apenas restrito significa, segundo Gauthier, agir em conformidade com os princípios de imparcialidade que caracterizam o agir moral. Mesmo uma organização para fins humanitários pode ser concebida, por paradoxal que seja, como um grupo de interesse comprometido antes de mais nada com a maximização do próprio interesse, na medida em que sua existência depende da existência mesma dos conflitos em que se envolve. Como afirma Andreas Hasenclever:

${ }^{42}$ Cf., por exemplo, Amy Gutmann, Identity in Democracy, 2003, p. 35-6. Cf. também Amartya Sen, 2002, "Justice across borders", p. 42-3.

43 Transformations of Citizenship: Dilemmas of the Nation State in the Era of Globalization, 2000, p. 48: ".... increasingly world public opinion, as well as a plethora of citizens's groups, transnational NGO's, international organizations and relief workers (Médecins sans Frontières and Amnesty International, for example) are creating 'counter-publics', who speak up in the name of refugees and asylees, sometimes litigating for their rights against their national governments, and vigilantly monitoring human rights abuses. The development of such institutions of 'international ethical advocacy' is also an aspect of the 'deterritorialization of politics' and political globalization". Sobre o conceito de "associações voluntárias" no contexto de Estados liberais democráticos, ver Amy Gutmann, op. cit. p. 86-116.

${ }^{44}$ Cf. e.g. Mônica Herz e Andréa Hoffmann, "Sociedade civil global", in Organizações Internacionais: História e Práticas, 2004, p. 232-253. 
Für die Medien haben humanitäre Krisensituationen einen Nachrichtenwert, für private Organisationen sind sie paradoxienweise die Existenzgrundlage und Abgeordnete dürfen hoffen, dass ihre Wähler und Wählerinen den Einsatz für Menschen in Not honorieren. Alle drei Akteursgruppen müssen mit anderen Worten nicht altruistisch handeln, sondern können durchaus ihr eigenes Fortkommen im Auge haben. ${ }^{45}$

Desta forma, as enormes desigualdades de natureza econômica, tecnológica e bélica, vigentes no âmbito da relação entre Estados, não representam uma objeção à tentativa de articularmos uma concepção de justiça de âmbito global fundada a partir da idéia do contrato social. Os participantes do "contrato", nesse sentido, não seriam apenas Estados, mas Estados e grupos de interesse. A efetiva participação de grupos de interesse no âmbito da "sociedade civil global" tende a minimizar as desigualdades vigentes no âmbito da relação entre Estados, na medida em que um Estado, ao buscar se valer de sua superioridade econômica, tecnológica e bélica sobre um outro Estado (ou grupo de Estados), tem de contar, cada vez mais, com a reação adversa de uma pluralidade de grupos de interesse. Esse tipo de reação adversa exerce, no âmbito das relações internacionais, o mesmo papel que as sanções informais da moral exercem no contexto de nossas práticas morais. Elas atuam como um desestímulo à tentativa de implementarmos de modo irrestrito a maximização do auto-interesse. É bem verdade, por outro lado, que as sanções informais, no âmbito das relações internacionais, nem sempre são suficientemente fortes para impedir que um Estado busque implementar de modo irrestrito seu interesse. No contexto da política doméstica, esse problema é resolvido através da positivação das sanções informais da moral. À tentativa de se implementar, de modo irrestrito, o auto-interesse, segue-se então uma penalidade imposta pelo Estado. Assim, a sanção deixa de ser meramente informal e se torna propriamente jurídica. No âmbito das relações internacionais, isso não é possível, pois as sanções informais, nesse caso, não podem ser exercidas por uma instância supra-estatal, análoga ao Estado no contexto da política doméstica. A criação de uma instância superior de caráter supra-estatal representaria mesmo uma ameaça àquilo que caracteriza um Estado enquanto tal, a saber: sua soberania. Por outro lado, no entanto, essa concepção tradicional de soberania, que começou a se consolidar a partir da Paz de Vestfália em 1648, tem sido bastante questionada nas últimas décadas. Uma razão para re-examinarmos a concepção tradicional de soberania já foi mencionada: a emergência de diversos grupos de interesse no cenário internacional tem representado um problema para a concepção tradicional de soberania, porque a política que um Estado adota, no que se refere a questões de ordem econômica, ecológica, ou política, tem sofrido cada vez mais influência das sanções informais que podem ser exercidas pelos diversos grupos de interesse de âmbito internacional. Um Estado pode, por exemplo, continuar a afirmar retori-

5 Die Macht der Moral in der internationalen Politik: Militärische Interventionen westlicher Staaten in Somalia, Ruanda und Bosnien-Herzegowina, 2000, p. 209. Sobre o papel da mídia no contexto de crises humanitárias, ver, por exemplo, Nicholas J. Wheeler e Alex J. Belamy, "Humanitarian intervention and world politics", p. 479-80. 
camente sua soberania sobre uma vasta extensão de floresta tropical, ao mesmo tempo que sua política doméstica, para o uso desta parte de seu território, não é indiferente às demandas de uma diversidade de grupos de interesse de alcance internacional. De modo análogo, um Estado (ou grupo de Estados) pode retoricamente afirmar não ceder, por exemplo, a pressões de grupos terroristas, ao mesmo tempo que faz concessões para o benefício de Estados (ou candidatos a Estados), em prol dos quais algumas das demandas de grupos terroristas são feitas, sem que, porém, tais concessões sejam publicamente justificadas como o resultado de algum tipo de barganha ou pressão externa. ${ }^{46}$ Há, nesse segundo caso, evidentemente, uma dificuldade especial, pois compreender uma organização terrorista como um dos grupos de interesse que participariam de um hipotético contrato social de âmbito global significaria reconhecê-la como um parceiro em um esquema de cooperação para benefício mútuo. Organizações terroristas não precisam ser reconhecidas como participantes de um contrato social de âmbito global. Mas elas, de todo modo, influenciam os termos desse contrato: em primeiro lugar, porque podem fazer demandas em prol de efetivos participantes do contrato; em segundo lugar, porque, na medida em que são reconhecidas como uma ameaça ao sistema de Estados como um todo, exigem dos Estados medidas coletivas, contribuindo, portanto, para a consolidação de um esquema de cooperação já existente. ${ }^{47}$

Uma segunda razão para re-examinarmos a concepção tradicional de soberania decorre da constatação de que a implementação do auto-interesse, em alguns casos, pode ser obtida pelo exercício coletivo da soberania. Com outras palavras, a própria soberania pode se tornar, como afirma Robert Keohane, uma espécie de "instrumento de barganha" (bargaining resource) na busca pela implementação do auto-interesse. ${ }^{48}$ A experiência da União Européia, nesse sentido, parece mostrar que o exercício coletivo da soberania no âmbito, por exemplo, de políticas econômicas, representa para os Estados-membros da União Européia uma maximização do auto-interesse na área econômica superior à maximização passível de ser obtida através do exercício individual - e portanto, tradicional - da soberania. Como afirma Robert Jackson, em referência à literatura recente sobre o conceito de soberania no contexto da União Européia:

46 Para uma discussão sobre as "demandas" de grupos terroristas e sobre o modo como elas representam um problema para a concepção tradicional de soberania no sistema internacional, ver, e.g., Barak Mendelsohn, "Sovereignty under attack: the international society meets the Al Qaeda network", 2005, p. 57s. Ver também Ernst-Otto Czempiel, Weltpolitik im Umbruch: Die Pax Americana, der Terrorismus und die Zukunft der internationalen Beziehungen, 2002.

${ }^{47}$ Cf. Barak Mendelsohn, op. cit., p. 66: “Terror organisations inherently challenge state's domestic sovereignty. However, at the same time, most terror organisations, in their quest for statehood, or by forcing states to put their difference aside to cooperate against the threat, reinforce the sovereigntybased IS (International System)".

48 Cf. Robert Keohane, "Hobbes' dilemma and institutional change in world politics: sovereignty in international society", 1995, p. 177. 
[...] the members states of the European Union are said to recognize that the instrumental value of sovereignty today is not as great as it used to be. EU states believe that they cannot effectively pursue their interests or concerns within the traditional framework of sovereignty. They are in the course of abandoning that old framework. ${ }^{49}$

Exercer de modo coletivo a soberania, evidentemente, não significa delegar a uma instância supra-estatal o poder que, até então, era exercido unicamente nos limites das instituições do próprio Estado; não significa também submeter-se a uma constituição comum a diferentes Estados. Exercer de modo coletivo a soberania significa participar de um esquema de cooperação mútua em que, por interesse próprio, alguns Estados permitem que outros Estados intervenham em certas esferas de atividades em que, tradicionalmente, a própria soberania do Estado se manifesta, tal como, por exemplo, a esfera da política econômica. Esse tipo de esquema de cooperação, como o representado pelo caso da União Européia, decorre de um "contrato" fatual entre os diversos atores envolvidos. Os atores em questão, em um determinado momento, optaram pela realização desse contrato. Compreendido nesses termos, o contrato não é meramente hipotético, mas real. Por outro lado, não é necessário que tenhamos em mente um contrato real para que possamos explicar a estrutura de um esquema cooperativo através da idéia do contrato social. Na tradição do contrato social, a idéia do contrato, como se sabe, não foi de modo geral defendida em termos fatuais, i.e., como alusão a um evento na história da humanidade, ou como algo que deveria ocorrer para que as desvantagens do estado de natureza pudessem ser superadas. Mesmo Hobbes reconheceu que sua descrição do estado de natureza, no capítulo 13 do Leviathan, não se refere a um período na história da humanidade durante o qual os indivíduos teriam vivido sem a instituição das leis, do Estado, da propriedade privada, e da justiça. ${ }^{50}$ O que interessa a Hobbes é mostrar que esta seria a condição humana, se essas instituições não existissem. A melhor maneira, então, de justificarmos a existência dessas instituições é, segundo Hobbes, recorrermos à idéia de um contrato. Outros importantes representantes da tradição do contrato social, tais como Kant e Rawls, foram mais explícitos em se referirem ao estatuto do contrato como "uma simples idéia da razão" (eine bloße Idee der Vernunft), ou como sendo meramente hipotético. ${ }^{51} \mathrm{O}$ sistema de sanções informais vigente no âmbito das relações internacionais, a meu ver, pode, da mesma maneira, ser compreendido como resultado de um contrato hipotético entre os diversos atores do sistema internacional, a saber: Estados e grupos de interesse.

49 Robert Jackson, "Introduction: sovereignty at the millennium", 1999, p. 426. Cf. também C. Bretherton e J. Vogler, The European Union as an International Actor, Londres, Routledge, 1999.

50 Cf. Leviathan, cap. 13: "It may peradventure be thought, there was never such a time, nor condition of warre as this; and I believe it was never generally so, over all the world..."

51 Cf. Kant, Über den Gemeinspruch: Das mag in der Theorie richtig sein, taugt aber nicht für die Praxis (Sobre a Expressão Corrente: Isto Pode Ser Correto na Teoria, Mas Nada Vale na Prática, 1793), 1983, p. 153. Rawls, The Law of Peoples, p. 10. Cf. também Stemmer, "Moralischer Kontraktualismus", 2002, p. 13-17. 


\section{VIII}

A meu ver, a única forma de tornarmos inteligível o conceito de direitos humanos como referência a um tipo de entidade normativa de caráter internacional, sem apelarmos a idéias metafísicas, é através de uma teoria do contrato social. Como bem mostra Bentham em Anarchical Fallacies, onde ele critica a teoria dos "direitos naturais", subjacente ao texto da Declaração dos Direitos do Homem e do Cidadão de 1789, direitos só existem no contexto de governos. Na ausência de um sistema de restrições mútuas, socialmente constituído, o que há, na verdade, é apenas o desejo de termos direitos. Seria, portanto, um equívoco confundirmos o desejo de termos direitos com os próprios direitos..$^{52} \mathrm{O}$ fato de alguns direitos serem fundamentais para a dinâmica da vida social levou autores como Grotius e Locke a assumirem que esses direitos já existiriam, de alguma forma, anteriormente mesmo à vida social, como se fossem propriedades inalienáveis dos indivíduos. Contudo, não é possível afirmarmos que objetos como "direitos naturais" existam, sem nos comprometermos também com a existência de entidades metafísicas ou sem nos comprometermos com uma concepção metafísica de pessoa. Anteriormente à constituição da comunidade política, o que há é unicamente a vontade de constituirmos um sistema de governo em que entidades normativas como direitos fundamentais - ou direitos humanos - sejam criadas. Nossa vontade de termos direitos, ela própria, pode ser justificada, a partir de diferentes perspectivas: a partir de uma teoria filosófica acerca, por exemplo, do conceito de autonomia; a partir de considerações sobre o auto-interesse; ou a partir de uma concepção religiosa de mundo. ${ }^{53}$ No entanto, na ausência de um sistema de restrições mútuas, o que temos não são ainda direitos, mas exigências morais, exigências meramente prudenciais, ou exigências religiosas. É apenas no contexto de um sistema de restrições mútuas que tais exigências se transformam propriamente em direitos fundamentais - ou direitos humanos. No plano doméstico, esse sistema de restrições é proporcionado pelo Estado. Se o texto da Declaração dos Direitos do Homem e do Cidadão exprime, através da linguagem dos "direitos naturais", o ideal do Estado liberal moderno, no contexto do qual tal sistema de restrições mútuas seria assegurado, coube ao texto da Declaração Universal dos Direitos Humanos, apresentado pelas Nações Unidas em 1948, buscar estender esses mesmos direitos à esfera bem mais ampla da comunidade internacional. No entan-

52 Cf. Bentham, Anarchical Fallacies, p. 53: "In proportion to the want of happiness resulting from the want of rights, a reason exists for wishing that there were such things as rights. But reasons for wishing there were such things as rights, are not rights; - a reason for wishing that a certain right were established, is not that right - want is not supply - hunger is not bread. [...] Natural rights is simple nonsense: natural and imprescriptible rights, rhetorical nonsense, - nonsense upon stilts".

53 A Declaração Universal dos Direitos Humanos no Islam, de 1981, busca claramente justificar o texto da declaração a partir de uma concepção religiosa de mundo; cf. Bundeszentrale für Politische Bildung, Menschenrechte: Dokumente und Deklarationen, 1999, p. 619-645. Com relação a esse ponto especificamente, a declaração islâmica de 1981 não se diferencia muito do texto da declaração americana, de 1776, que afirma o seguinte: "We hold these truths to be self-evident, thal all men [...] are endowed by their Creator with certain unalienable rights; that among these are life, liberty, and the pursuit of happiness". 
to, na ausência de um sistema de restrições mútuas de âmbito internacional, esses "direitos" eram, na época de sua declaração, meros ideais: eles exprimiam uma aspiração de um amplo segmento da comunidade internacional, no sentido de que aqueles mesmos direitos, que já existiam no contexto de Estados liberais democráticos, pudessem também existir no plano internacional. Como reconhece, por exemplo, Kenneth Abbot, esses "direitos" tinham inicialmente um caráter meramente "aspiracional". Foi somente mais tarde que eles se tornaram "obrigações legais vinculatórias" (binding legal obligations). ${ }^{54}$ Mas, na ausência de um sistema de sanções formais, como aquele vigente no interior dos Estados, é preciso que haja, pelo menos, um sistema de sanções informais no contexto do qual essas obrigações possam realmente existir. O que tentei mostrar neste capítulo é que esse sistema de sanções informais, vigente no âmbito das relações internacionais, pode ser concebido como resultado de um contrato hipotético do qual fariam parte Estados e grupos de interesse.

\section{Referências}

ABBOTT, Kenneth; KEOHANE, Robert; MORAVCSIK, Andrew, et alii: "The concept of legalization", in International Organization, vol. 54, 2000, p. 401-419.

BEITZ, Charles R.: Political Theory and International Relations, Princeton. Princeton: University Press, 1979.

BENHABIB, Seyla: The Claims of Culture: Equality and Diversity in the Global Era. Princeton: Princeton University Press, 2002.

Transformations of Citizenship: Dilemmas of the Nation State in the Era of Globalization. Amsterdam: Koninklijke van Gorcum, 2001.

BENTHAM, Jeremy: "Anarchical Fallacies", in (org.) J. Waldron, Nonsense upon Stilts: Bentham, Burke and Marx on the Rights of the Man. Londres: Metheuen, 1987.

BICCHIERI, Cristina: "Reputation", in Rationality and Coordination. Cambridge: Cambridge University Press, 1995, p. 188-192.

BRETHERTON e VOGLER, J.: The European Union as an International Actor. Londres: Routledge, 1999.

BROWN, Chris: International Relations. Londres: MacMillan, 1997.

BULL, Hedley: Anarchical Society: A Study of Order in World Politics. Columbia: Columbia University Press, 1977.

BUNDESZENTRALE FÜR POLITISCHE BILDUNG: Menschenrechte: Dokumente und Deklarationen. Bonn, 1999.

CANEY, Simon: "Humanitarian intervention and state sovereignty", in (org.) Andrew Valls. Ethics and International Affairs: Theories and Cases, 2000. New York: Rowman \& Littlefield, p. 117-133.

54 Keneth Abbot, Robert Keohane et alii, "The concept of legalization", in International Organization, vol. 54, 2000, p. 405: "The Universal Declaration of Human Rights, for example, was only minimally legalized (it was aspirational, not overly precise, and weakly institutionalized), but the human rights regime has evolved into harder forms over time. The international Covenant on Civil and Political Rights imposes binding legal obligations, spells out concepts only adumbrated in the declaration, and creates (modest) implementing institutions [...] The declaration has also contributed to the evolution of customary law, which can be applied by national courts as well as international organs, and has been incorporated into a number of national constitutions". 
CARENS, Joe: "Aliens and citizens: the case for open borders", in (org.) Roland Beiner. Theorizing Citizenship. New York: Suny Press, 1995, 229-255.

CAVALLAR, Georg: "Kant's society of nations: free federation or world republic?" in Journal of the History of Philosophy, 1994, vol. 32, p. 461-482.

CHARVET, John: "International society from a contractarian perspective", in (orgs.) David R. Mapel e Terry Nardin. International Society: Diverse Ethical Perspectives. New Jersey: Princeton University Press, 1998, p. 114-131.

CHARVET, John: "Contractarianism and international political theory", in (orgs.) David Boucher e Paul Kelly. The Social Contract from Hobbes to Rawls. Londres: Routledge, 1994, p. 175-190.

CHWASZCZA, Christine: "Anmerkungen zur vertragstheoretischen Begründung globaler Gerechtigkeit", in (org.) G. Meggle: Analyomen 2: Proceeding of the 2nd Conference "Perspectives in Analytical Philosophy", vol. 3. Berlim: De Gruyter, 1997, p. 212-219.

CZEMPIEL, Ernst-Otto: Weltpolitik im Umbruch: Die Pax Americana, der Terrorismus und die Zukunft der internationalen Beziehungen. Bonn: Bundeszentrale für politische Bildung, 2002.

DESSLER, Jack: "Twentieth-Century Realism", in (orgs.) Terry Nardin e David R. Mapel. Cambridge: Cambridge University Press, Traditions of International Ethics, 1992.

DINGENMANN, Rüdiger: Krisenherde der Welt: Konflikte und Kriege seit 1945: Daten, Fakten, Hintergrund. Munique: Westermann, 1996.

DODSON, Kevin: Kant's Perpetual Peace: universal civil society or league of states? in: Southwest Philosophical Studies, vol. 15, p. 1-9, 1993.

FORDE, Steven: "Classical Realism", in (orgs.) Terry Nardin e David R. Mapel. Cambridge: Cambridge University Press, Traditions of International Ethics, 1992, p. 62-84.

FRANCESCHET, Antonio: "Sovereignty and freedom: Immanuel Kant's liberal internationalist 'legacy'”. Review of International Studies, vol. 27, 2001. p. 209-228.

GAUTHIER, David: "Gauthier" (entrevista), in A. Pyle, Key Philosophers in Conversation. Londres: Routledge, 1999, p. 129-141.

. "Between Hobbes and Rawls", in (org.) D. Sugden, Rationality, Justice and the Social Contract: Themes from Morals by Agreement. Ann Arbor: The University of Michigan Press, 1993, p. 24-39.

."Why contractarianism?", in P. (org.) Vallentyne, Peter: Contractarianism and Rational Choice. Cambridge: Cambridge University Press, 1991, 15-30.

Morals by Agreement. Oxford: Oxford University Press, 1986.

The Logic of Leviathan: The Moral and Political Theory of Thomas Hobbes. Oxford: At the Clarendon Press, 1967.

GILPIN, R.: "The richness of the tradition of political realism", in (org.) R. Keohane. Neorealism and Its Critics. New York: Columbia University Press, 1986, p. 301-321.

GUTMANN, Amy: Identity in Democracy. Oxford: Oxford University Press, 2003.

HAMPTON, Jean: "Modern social contracts theories", in Political Philosophy. Oxford: Westview Press, 1998, p. 39-69.

HASENCLEVER, Andreas: Die Macht der Moral in der internationalen Politik: Militärische Interventionen westlicher Staaten in Somalia, Ruanda und Bosnien-Herzegowina. Frankfurt: Campus Verlag, 2000.

HAUSS, Charles: International Conflict Resolution: International Relations for the 21st Century. Londres: Continuum, 2001.

HERZ, Mônica e HOFFMANN, R. Andrea: Organizações Internacionais: História e Práticas. Rio de Janeiro: Elsevier, 2004.

HOBBES: A Dialogue between a Philosopher and a Student of the Common Laws of England. Chicago: The University of Chicago Press, 1997.

. Leviathan (1651). Cambridge: Cambridge University Press, 1996 
On the Citizen (1642), trad. Richard Tuck e Michael Silverthrone. Cambridge: Cambridge University Press, 1998.

INTERNATIONAL COMMISSION ON INTERVENTION AND STATE SOVEREIGNTY: The Responsibility to Protect: Report of the International Commission on Intervention and State Sovereignty. Ottawa: International Development Research Center, 2002.

JACKSON, Robert: "Introduction: Sovereignty at the millennium", in Political Studies, vol. 47, 1999, p. 423-430.

KAHLER, Miles: "Inventing international relations: international relations theory after 1945", in (orgs.) M. W. Doyle e G. J. Ikenberry. New Thinking in International Theory. Oxford: Westview Press, 1997, p. 20-53.

KANT: Kant: Werke in Zehn Bänden, editado por Wilhelm Weischedel. Darmstadt: Wissenschaftliche Buchgesellschaft, 1983.

KEOHANE, Robert: "Hobbes dilemma and institutional change in world politics: sovereignty in international society", in (orgs.) H. H. Holmes e G. Sorensen: Whose World Order: Uneven Globalization and the End of Cold War. Westview: Boulder Co., 1995, p. 165-86.

LAUBACH-HINTERMEIER, S.: "Kritik des Realismus", in Politische Philosophie der internationalen Beziehungen, (orgs.). C. Chwaszcza e W. Kersting. Frankfurt: Suhrkamp, 1998, p. 73-95.

LONG, D. e WILSON, P.: Thinkers of the Twenty Years' Crisis. Oxford: Clarendon Press, 1995.

MAPEL, David R.: "The contractarian tradition and international ethics", in (orgs.) Terry Nardin e David R. Mapel. Cambridge: Cambridge University Press, Traditions of International Ethics, 1992, p. 180-200.

MACKIE, J. L.: Ethics: Inventing Right and Wrong. Harmondsworth: Penguin Books, 1977. MENDELSOHN, Barak: "Sovereignty under attack: the international society meets the Al Qaeda network", in Review of International Studies, vol. 31, 2005, p. 45-68.

MILLER, David: "Holding nations responsible", in Ethics, vol. 114, 2004, p. 240-268.

MOORE, Margaret: "Gauthier's contractarian morality", in (orgs.) David Boucher e Paul Kelly. The Social Contract from Hobbes to Rawls. Londres; Routledge, 1994, p. 211-225.

MORGENTHAU, Hans: Politics Among Nations. New York: McGraw-Hill, 1967.

MORRIS, Christopher W.: "The relation between self-interest and justice in contractarian ethics", in Social Philosophy and Policy (edição especial intitulada Gauthier's New Social Contract), vol. 5, 1988, 119-153.

NOGUEIRA, João Pontes: "A guerra do Kosovo e a desintegração da Iuguslávia: Notas sobre a (re)construção do Estado no fim do milênio", in Revista Brasileira de Ciências Sociais, vol. 15, 2000, 143-160.

PALMERSTON, Henry John Lord: "The balance of power defended" (1864), in (org.) Evans Luard. Basic Texts in International Relations. MacMillan, 1993, p. 444-445.

POGGE, Thomas: "An egalitarian law of peoples", in Philosophy and Public Affairs, 1994, vol. 23, p. 295-224.

POGGE, Thomas: Realizing Rawls. New York: Ithaca, Cornell University Press, 1989.

RAWLS, John: The Law of Peoples. Cambridge (Massachusetts): Harvard University Press, 1999.

. A Theory of Justice (1971). Cambridge (Massachusetts): Harvard University Press, 1999.

ROSENAU, James N.: "Sovereignty in a turbulent world", in (orgs.) M. Grene Lyons e Michael Mastanduno: Beyond Westphalia? State Sovereignty and International Intervention. Baltimore: Hopkins University Press, 1995, p. 191-227.

"Governance, order, and change in world politics", in (orgs.) James Rosenau e Ernst-Otto Czempiel. Governance without Government: Order and Change in World Politics. Cambridge: Cambridge University Press, 1992, p. 1-29. 
SEN, Amartya: "Justice across borderss", in (orgs.) Pablo De Greiff e Ciaran Cronin. Global Justice and Transnational Politics: Essays on the Moral and Political Challenges of Globalization. Cambridge (Massachusetts); The MIT Press, 2002, p. 37-51.

STEMMER, Peter: "Der Begriff der moralischen Pflicht", in (org.) Anton Leist, Moral als Vertrag? Beiträge zum moralischen Kontraktualismus. Berlin: De Gruyter, 2003, p. 37-70.

$1-21$.

. "Moralischer Kontraktualismus", in Zeitschrift für philosophische Forschung, vol. 56, 2002, p. 2000

Handeln zugunsten anderer: Eine moralphilosophische Untersuchung. Berlin: De Gruyter,

THOMAS, Ward: The Ethics of Destruction: Norms and Force in International Relations. Ithaca: Cornell University Press, 2001.

WEINAR, Leif: "The legitimacy of peoples", in (orgs.) Pablo De Greiff e Ciaran Cronin. Global Justice and Transnational Politics: Essays on the Moral and Political Challenges of Globalization. Cambridge (Massachusetts): The MIT Press, 2002, p. 53-76.

WHEELER, Nicholas J. e BELAMY, Alex J.: "Humanitarian intervention and world politics", in (orgs.) John Bayles e Steve Smith. The Globalization of World Politics: An Introduction to International Relations. Oxford: Oxford University Press, 2001, p. 470-493.

WIGHT, Martin: "The balance of power", in Power Politics. Leicester University Press, 1995, p. 168-185.

WILLETTS, Peter: "Transnational actors and international organizations in global politics", in (orgs.) John Bayles e Steve Smith. The Globalization of World Politics: An Introduction to International Relations. Oxford: Oxford University Press, 2001, p. 356-383.

ZANETTI, Véronique: "Ethik des Interventionsrechts", in Politische Philosophie der internationalen Beziehungen, (orgs.) C. Chwaszcza e W. Kersting. Frankfurt: Suhrkamp, 1998, p. 297-324. 